\title{
Causative-inchoative Alternation in the Language of Jordanian EFL Learners
}

\author{
Yazan Shaker Almahameed ${ }^{1 *}$, Mohammad Mansour Al-Aajalein ${ }^{2}$, Khawlah Mohammad Ahmad ${ }^{3}$ \\ ${ }^{1,3}$ Department of English language and translation, Amman Arab University, Jordan, \\ ${ }^{2}$ Ministry of Education, Jordan
}

Corresponding Author: Yazan Shaker Almahameed, E-mail: Yazan.shaker@yahoo.com

\begin{tabular}{l} 
ARTICLE INFO \\
\hline Article history \\
Received: June 06, 2018 \\
Accepted: August 18, 2018 \\
Published: November 01, 2018 \\
Volume: 7 Issue: 6 \\
Advance access: September 2018 \\
\hline
\end{tabular}

Conflicts of interest: None Funding: None

\begin{abstract}
Causative-inchoative construction is a pair of verbs discussing the same notion, which is a state of change with a different form for each verb. It has been noted that causative-inchoative alternation constitutes a learnability problem for Arab EFL learners and very few studies addressed this language form among Arab learners and more specifically Jordanian learners of English. The present study is an attempt to measure the perception and production of English causative-inchoative alternations by learners whose native language is Arabic. In collecting the required data for the study, grammaticality judgement and correction task was used. A total of 24 Jordanian English majors partook in the study. Having analyzed the data statistically, the study results depicted that comprehending and producing causative and inchoative constructions by Jordanian English majors is not an easy task. It was also found that causative structures are more readily to acquire than their inchoative counterparts. More precisely, it could be argued that Jordanian learners of English acquire the causative form earlier than the inchoative form. Finally, the results revealed that language transfer is the driving force of acquiring causative-inchoative structures, where a great deal of errors can be traced back to Arabic. The study arrived at the conclusion that the participants have a weak competence of causative-inchoative forms which is best exhibited in their responses to the items of grammaticality judgement task. This conclusion could be attributed to the fact that Arabic and English vary greatly with respect to encoding causative-inchoative forms.
\end{abstract}

Key words: Causative-inchoative Constructions, English Majors, Language Transfer; Grammaticality Judgement Task

\section{INTRODUCTION}

The semantic relationship between a verb and its argument is represented in two ways; the first way is causative construction which implies that the agent is the subject and the patient is the object of the argument. The second way of expressing verb-argument relationship is inchoative construction, where the patient plays the role of the subject in the sentence (Fontenelle and Vanandroye 1989, cited in Dziemianko, 2006, P. 57). To be more specific, causative- inchoative alternation is a pair of verbs expressing the same notion, mostly a state of change, however each construction has a distinctive form. While, causative form requires the presence of an agent participant who causes the action, inchoative form does not entail such agent participant, replacing it with a patient and the action is revealed as taking place spontaneously. Causative verbs are counted as transitive in nature, expressing the notion of bringing about the change of state, whereas inchoative verbs are counted as the intransitive form, donating spontaneous change of state (Pinon,
2001). The so-called intransitive inchoative construction is characterized by the fact that, the object -verb semantic relationship is the same as that of subject-verb in the causative or transitive construction.

The two examples below depict how causative-inchoative alternations are formed in English. The first example illustrates the case of causative construction, while the second example displays inchoative construction.

A- The door opened

B- David opened the door

Sentence A is an example of the inchoative use, where A has only a single argument of the verb opened, which is "the door". In this sentence, the argument "the door" is not the cause of action but has the same semantic characteristics as well as the syntactic position of the agent or doer of action. Inchoative form entails the presence of an internal participant who brings about change of state as manifested in the argument "the door". In contrast, sentence B is an example of the causative form. In sentence B "the door" is the direct object of the predicate "opened", and the actual cause 
of action is exhibited in the form of David. Accordingly, causative construction involves external participant, causing a change to the state.

It is of a paramount importance to indicate that the inchoative construction has been a matter of heated debate among researchers with respect to its relationship with passive voice. Some linguists categorized inchoative construction under passive form like Tabib-Zadeh (2006) who argues that inchoative verbs can be treated as a type of passive use. However, other linguists went counter Tabib-Zadeh's argument like Richards, etl (1992) who maintain that despite the superficial similarity between inchoative and passive structures, in that both choose the patient as their syntactic agent, the agent appears in passive implicitly while in inchoative structure there is no presence of the agent. For the sake of illustration, let us consider the examples to follow.

$\mathrm{C}$ - The window is broken

D- The window breaks

The agent or causer of action is not mentioned in either sentences ( $\mathrm{C}$ and $\mathrm{D})$. However, in C "the passive form" the meaning necessitates the presence of an agent even though it is not stated overtly. In contrast, the meaning of sentence $\mathrm{D}$ does not indicate the existence of an agent, neither overtly nor covertly.

According to Pinker (1989) English verbs can be grouped into two main categories in terms of causative/inchoative alternation. The first category is verbs permitting causative/ inchoative alternation, which can be further sub-divided into A-verbs exhibiting physical change e.g. melt, freeze, rise, drop, clean, feed, dry, burn, close, open, break, crack, rip, shatter, snap and fracture. B- verbs exhibiting manner of motion, which are comprised of e.g. bounce, drift, drop, float, glide, move, roll, slide, swing, run, gallop etc. The second category is verbs that do not allow causative/inchoative alternation. This category includes, A- verbs indicating cutting (cut, hack, saw scratch, slash, chip, clip, scrap, scratch, hew ...). B- verbs indicating change of existence (appear, disappear, vanish, emerge ...). C- verbs indicating action (talk, walk, eat, drink, sing ....). D-verbs indicating emission (glow, sparkle, blaze, bubble ...). Pinker based his argument on the fact that, some verbs do not accept causativelinchoative alternation as they necessitate the presence of agent, while others accept such alternation because they describe an action as taking place spontaneously or caused by natural forces e.g. wind, snow, whether, gravity.

The sub-systems of Arabic and English are largely diverse, as the two languages belong to two different families. Arabic is a member of Semitic family, whereas English refers to Germanic family (Alhaj, 2015). Such diversity is best exhibited in the use of causative and inchoative constructions in the two languages, meaning that encoding those two structures is largely dissimilar in both English and Arabic. In other words, while some Arabic verbs accept alternating with their English counterparts e.g. break, open, close, burn, etc... Many other verbs reject such type of alteration e.g. kill, cut, hit, kick, write, destroy, bother, annoy etc. It could be said that, encoding inchoative and causative systems differently in English and Arabic creates learnability problems for Arab
EFL learners. This is consistent with El-nabih (2010) who concluded that acquiring causative and inchoative structures constitutes a challenge for Arab learners of English and poses considerable difficulties that clearly appear in the language of those learners. In addition, To the best of the researcher's knowledge no serious attempt has been made to test Arab EFL learners' causative and inchoative competence excluding Elnabih (2010) and Zibin, and Altakhaineh. (2016), which entails conducting more studies in order to gain a deep insight into the acquisition of causative/inchoative constructions and to bridge a gap in literature by so doing. More specifically, among Jordanians learning English as L2.

Based on the above discussion, the current study seeks to fulfill the following objectives.

1- Examining Jordanian EFL learners' competence of causative and inchoative constructions.

2- Examining the most challenging construction to acquire between causative and inchoative constructions.

3- Gaining insight into L1 (Arabic) role in the acquisition of causative and inchoative constructions.

In other words, the study sets out to answer the following questions.

Q1) How do Jordanian EFL learners grasp causative/inchoative alternation?

Q2) Between the causative and inchoative constructions; which one is more readily to acquire?

Q3) To what extent does transfer from L1 (Arabic) contribute to the errors committed as acquiring causative and inchoative constructions?

\section{ENGLISH AND ARABIC CAUSATIVE/ INCHOATIVE ALTERNATION}

Causative-inchoative alternation is counted as a cross-linguistic phenomenon that exist approximately in all languages studied up to now (Schäfer, 2009). It is fitting to indicate that languages vary vastly in terms of encoding causative-inchoative alternation. More specifically, it was noticed that most alternating verbs across languages are lexical counterparts and some languages are morphologically marked " the same verb form is used for both causative and inchoative constructions", while other languages are unmarked " different verb forms are used for both causative and inchoative constructions" (Samardzic and Merlo 2012).

Based on the previously mentioned elaboration on causative-inchoative alternation across languages, the semantic relationship between English and Arabic alternating verbs is categorized into two main types as follows;

1- Some Arabic verbs permit alternating with their English lexical counterparts so that those verbs appear freely in causative/inchoative constructions in the two languages. However, those alternating verbs are recognized differently in the two languages; switching from causative case to inchoative case in Arabic causes morphological changes to the verb. In contrast, English causative/inchoative alternation is marked, where no morphological changes take place to the verb. The examples below depict the occurrence of causative/inchoative alternation in both English and Arabic. 
E-Yamin broke the window

F- The window broke

The two sentences above exemplify causative construction $\mathrm{E}$ and inchoative construction $\mathrm{F}$ in English. A close look at those examples indicate that alternating from causative construction to inchoative construction in English is not accompanied with any morphological changes. It goes without saying that the verb broke in the two sentences ( $E$ and $F$ ) bears no changes since English is morphologically marked with regard to this type of alternation.

G- Haraqa Alwaladu Alwaraqah

- $\quad$ The boy burned the paper

H- ?htaraqat Alwaraqah

- $\quad$ The paper burned

The above mentioned Examples ( $\mathrm{G}$ and $\mathrm{H}$ ) reveal the happening of causativelinchoative alternation in Arabic. In $\mathrm{G}$, the verb Haraqa represents causative case, while in $\mathrm{H}$ the verb Ihtaraqa represents inchoative case, thereby alternating from $\mathrm{G}$ to $\mathrm{H}$ is accompanied with basic morphological changes to the verb Haraqa. This is manifested by adding the glottal stop prefix? and the infix $t$.

2- Some Arabic verbs prohibit alternating with their English

lexical counterparts, meaning that some Arabic verbs occur freely in both constructions, while their English peers do not or vice versa. For the sake of gaining more insight, let us consider the following Examples.

I- The soldier killed his foe.

J-* The foe killed.

As shown in the examples above (I and J), alternating from causative construction to inchoative construction with the verb killed is illicit in English. However, the case is completely different with the same verb in Arabic.

K- Qatal Aljundiu Adwahu

L- Inqatala Aladw

Contrary to English, in Arabic the verb Qatala ' killed' accepts alternation, so that it is switched to the inchoative case Inqatala.

\section{THEORETICAL FRAMEWORK}

One of the most cited and working definitions of language transfer is that presented by Odlin $(1989$, p.27) who argues that "transfer is the influence resulting from similarities and differences between the target language and any other language that has been previously (and perhaps imperfectly) acquired". From this definition, one could infer that language transfer is divided into two types; positive resulting from similarities between two languages in contrast and negative resulting from differences between any two languages.

First language transfer (L1 transfer) is counted by a large body of researchers as a determining factor in the acquisition of a second language L2 (Fries, 1957; Gass and Silenkar, 1992; Odlin, 1989). This is in line with Odlin, (1989, p. 24) who points out that "much of the imperial research in the 1970s and 1980s has led to new and ever more persuasive evidence for the importance of transfer in all subsystems". One more evidence of the importance of language transfer comes from Ellis (1985) who states that " it is a popular belief that the second language acquisition (SLA) is strongly influenced by the learner's first language (L1)". Based on this assumption, an immense quantity of studies has been conducted to investigate the role played by L1 in the acquisition of all L2 sub-systems. Those studies were diverse in terms of results, in which some elevated the status of L1 transfer as the major driving force of L2 acquisition (E1nabih, 2010; Simic, 2010; Tahaineh, 2010), whereas other studies claim a trivial impact of transfer from mother tongue (Dulay and Burt, 1974; Bailey, Madden and Krashen (1974). Odlin (1989) plays down language transfer counter-argument by saying that the skepticism over the role of language transfer does not stem from empirical research.

In this regard, it is fitting to say that the role played by language transfer in the acquisition of second language structures constitutes the theoretical framework of the present study. To be more specific, this study seeks to provide additional evidence supporting the role of Arabic language transfer in the acquisition of English causative/inchoative alternation. Language transfer was attested nearly in all second language subsystems. However, there is a lack of empirical studies examining such role when acquiring causative/ inchoative alternations by learners whose native language is Arabic.

\section{RELATED LITERATURE}

A great deal of studies have been carried out within the framework of causative-inchoative alternation. Those studies were designed to serve diverse functions and to fulfill plenty of objectives. Some studies attempted at gaining insight into the role played by L1 in acquiring causative-inchoative constructions. Other studies sought to establish a comprehensive contrast between causative-inchoative structures in L1 and L2. This review of previous literature is not restricted to studies implemented on Arab learners of English as they are very scant, but mostly highlights the structures in question among English learners from different L1 backgrounds so as to attain thorough understanding of this type of alternation in English.

In this regard, one of the most influential studies that of Moore (1993) who tested the acquisition of causative-inchoative alternation by English Foreign Language EFL speakers. The participants represented various L1 backgrounds; Arabic, Chinese, Spanish, Korean and Japanese. With the aim of obtaining the data on the use of causative constructions, alternating and non-alternating uncausatives and unergative verb, the researcher employed controlled production task. The study arrived at the conclusion that all the participants irrespective of their L1s overgeneralized unergative verbs and non-alternating unaccusatives into the accusative. The results also show that the learners generated more instances of non-alternating unaccustaive verbs e.g. die, com, arrive and disappear than the unegrative verbs e.g. walk, drive and cry. Moore accounted for his results by stating that" the asymmetric preference might be due to the different argument structure of these two types of verbs. As for non-alternating unaccusative verbs, the theme role remained as the internal argument both in causative and inchoative constructions, while for unergative ones, the theme role 
changed from the agentive subject (in intransitive form) into some affected entity (in causative form)".

Another study reported by Montrul (1999, 2001a, b) who investigated the acquisition of causative/inchoative structures in English, Spanish and Turkish by learners whose native languages are Spanish, English, Turkish and Japanese. The findings of this series of studies indicated that the course of development in acquiring those languages was influenced by the morphological characteristics of L1. For instance, the results pertinent Spanish L2 denoted that learners native to English wrongly used inchoative verbs with reflexive markers and inappropriately allowed zero-morphological inchoatives. Montrul ascribed such results to the fact that the inchoative form in English is zero-inflectional which is reflected in the language of English learners of Spanish. Sharing, Montrul's results, Yip (1995) investigated the causative/inchoative forms by Chinese speakers of English. The researcher concluded that Chinese EFL learners did not accept English inchoative construction on the basis that the inchoative form in English is null-inflectional, contrary to its Chinese counterpart. In other words, the Chinese leaners kept adding the predicate "make" to the causative form and producing the passive in place of the inchoative form.

In line with the findings of the previously stated studies (Montrul,1999, 2001a, b; Yip,1995), Can and Altunkol(n.d) examined causative-inchoative alternation by Turkish learners of English. similar to English, Turkish allows causative-inchoative alternation but with a special grammatical device that change the state of verb as displayed in the examples ( $\mathrm{K}$ and $\mathrm{L}$ ) below.

$K$ - Ahmet kagidi yirtti.

Ahmet paper-acc tear-past

Ahmet tore the paper apart.

L- Kagit yirt-il-di.

Paper tear-anticaus-past

The paper tore.

A total of 41 subjects pursuing their English studies at Çukurova University, Adana took part in the study. The respondents were presented with three different tasks; 1- 40 item grammaticality judgement and correction task, 2- Preference task with 10 pictures, each of which has 10 alternating inchoative verbs and 3- Translation task with 17 Turkish sentences to be translated into English. The results of the study indicated that the participants performed poorly when producing alternating verbs due to having insufficient knowledge of causative-inchoative alternation. In addition, the results revealed that errors made by the respondents can be traced back to their L1.

In support of language transfer position, El-nabih (2010) investigated primarily the acquisition of English causative-inchoative alternation by Arab Palestinian learners of English. As a secondary objective, the study sought exploring whether learners' L1 operates as acquiring those alternating forms. It is fitting to indicate that both English and Arabic permit causative-inchoative alteration, with major differences in terms of forming the two constructions. In English, no morphological changes take place when alternating from causative to inchoative structures, while in Arabic morphological changes are mandatory as exemplified in the sentences below.

M- The ice melts

- yathubu ?ljaleed

$\mathrm{N}$-The sun melts the ice

-?thabat alshamsu ?ljaleed.

In eliciting the required data for the study, the researcher utilized a grammaticality judgement and correction task. 119 Palestinian students learning English as L2 partook in the study. The study came with conclusion that the Palestinian participants encountered difficulty acquiring English causative-inchoative alternation. According to the researcher, four non-target language behaviors were attested; overpassivization, overcausativization, underpassivization, and undercausativization. It was found that this learnability problem can, to a great extent, be ascribed to Arabic transfer.

In line with El-nabih (2010), Zibin, and Altakhaineh. (2016) investigated the acquisition of causative alternations by Arab EFL learners. The study aimed primarily to test the participants' ability in distinguishing between alternating and non-alternating verbs. A total of eighty students learning English as a second language participated in the study. For the purpose of eliciting the required data, the researchers utilized the means of grammaticality judgement and correction task. The results of this study indicated that the respondents confront difficulties learning some non-alternating verbs. The researchers attributed the difficulties encountered by the respondents to transfer from their L1 (Arabic).

Contrary to language transfer view, Zobl (1989) implemented a study on causative-inchoative alternation among EFL learners. The sample of the study comprised subject from several L1s including Japanese, Spanish, Arabic, Chinese, Indonesian, Thai and Turkish. In collecting the needed data, the researcher referred to written corpus of university students. Zobl argued that the respondents committed higher errors in the unaccusative form than the unergative form. He concluded that the attested errors did not stem from the subjects' L1s, for instance the Japanese learners of English produced a word order in unaccusatives unlike that found in both their native language (Japanese) and target language (English).

Having reviewed some previous studies investigating the acquisition of causative/inchoative alternation, it is worth noting that the results of those studies reflected two conflicting views. The first deems L1 transfer as the driving force of acquiring causative/inchoative structures (Yip, 1995; Montrul,1999, 2001a,b; Can and Altunkol n.d; El-nabih, 2010), whereas the second, contends that learnability problems encountered by L2 learners do not arise from L1 transfer (Zobl 1989; Moore,1993). All the previously reviewed studies targeted non-Arab EFL learners except for Moore's study (1993), which included learners from five L1 backgrounds including Arabs and El-nabih (2010), which can be counted as the only study concentrating on Arab learners of English. The scarcity of studies on Arab speakers of English creates an urgent need to test causative/inchoative alternation among Arab EFL learners. 


\section{METHODOLOGY}

This section outlines the method used to collect the needed data with the aim of answering the previously stated research questions. In this section, the sample, instruments and data analysis are presented.

\section{Sample}

The sample of the present study is comprised of 24 participants who study English as a foreign language at Amman Arab University in Jordan. The sample was selected randomly using simple random sampling process, so that the researcher prepared a list of students' names in each class and chose every other name to partake in this study. The sample represents all academic years from first to forth, and includes both genders. The vast majority of the participants have never been to an English speaking country, thereby, they have an equal exposure to English.

\section{Instruments}

In collecting the required data for the acquisition of causative and inchoative constructions, the researcher utilized the means of grammaticality judgement and correction task. This task is the most appropriate to measure the acquisition of causative and inchoative structures since the task enables the researcher measure respondents' preference of one construction over another. In addition, grammaticality judgement and correction task enables the researcher to investigate the learners' competence of causative and inchoative forms as the respondents are instructed to first judge the items in terms of complying with semantic and grammatical rules, then to correct the items judged as erroneous. Many researchers recommended the use of grammaticality judgement and correction task as a reliable instrument to measure the linguistic competence of L2 learners (Chaudron, 1983; Elnabih, 2010; Liao, 2010).

The task administered to the respondents is split into three parts; part A is comprised of eight items on the causative use in which six sentences are incorrect and two are correct. Part B is also composed of eight items; of which six correct sentences and two incorrect. Part B is designed to measure the respondents' competence in the inchoative use. Part C contains five pairs of sentences, where each pair includes a sentence on the causative use and a sentence on the inchoative use. In responding two parts A and B of the test, the participants are instructed to accomplish two main tasks; first, judging each item with respect to grammaticality and meaningfulness. Second, correcting the items that are judged as incorrect. As for part $\mathrm{C}$, the participants are required only mark the item they think as correct in each pair of sentences. Providing that they think the two items are correct, they can mark both items. The aim beyond designing part $\mathrm{C}$ is to examine which construction; causative or inchoative is acquired earlier by the respondents.

\section{Data Analysis}

This study is descriptive in nature. It is argued that descriptive statistics are employed to describe specific properties of the sample of the study (Rubin and Babbie,2009). Many types of descriptive statistics were utilized in this study such as percentage, frequency and t-test. Percentage and frequency were used to gain numerical data regarding the respondents' production of causative-inchoative constructions. While, t-test was employed in order to determine any statistical differences in the use of causative and inchoative forms.

\section{THE RESULTS}

This section reveals the results of this research study based on the data collected from the subjects. In this review of results, the study endeavors to provide satisfactory answers to the three research questions raised formerly. The beginning is with the results of question one which is formulated as follows;

\section{Jordanian EFL Learners' Perception Of Causative- Inchoative Alternations.}

\section{Q1) How do Jordanian EFL learners perceive causative/ inchoative alternation?}

The results pertinent to this question are viewed in Table 1 below, which depicts subjects' responses to the items of grammaticality and judgement task.

Based on the figures obtained from Table 1, the total percentage of participants' responses related to the use of causative and inchoative constructions is $37.7 \%$. To be more specific, causative construction was employed 89 times when responding to the items of grammaticality judgement task, constituting $21.3 \%$ of total responses. It is also demonstrated that inchoative construction was used 48 times, with a percentage of $11.4 \%$. Having revealed the proportion of relevant responses (the case of causative and inchoative constructions), the figures of irrelevant responses are shown in Table 2 below.

In answering to the items of Grammaticality judgement task, the subjects provided responses irrelevant to causative and inchoative constructions. Those irrelevant responses are divided into three main categories; 1 - cases where the respondents overgeneralize causative/inchoative structures into passive voice, which is named passive responses. 2- cases where the respondents provided incorrect responses that can be ascribed to their native language, which is named language transfer responses. 3- cases where the respondents provided incorrect responses that.

That might be attributed to intralingual interference. Table 2 displays that the total percentage of subjects' irrelevant responses is $67.3 \%$. The table also indicates that language transfer constitutes the highest percentage of irrel-

Table 1. Subjects' relevant responses

\begin{tabular}{lcc}
\hline & $\begin{array}{c}\text { Frequency of } \\
\text { relevant responses }\end{array}$ & $\begin{array}{c}\text { Percentage of } \\
\text { relevant responses }\end{array}$ \\
\hline Causative & 89 & 21.3 \\
Inchoative & 48 & 11.4 \\
Total & & 37.7 \\
\hline
\end{tabular}


Table 2. Subjects' irrelevant responses

\begin{tabular}{|c|c|c|}
\hline Type of Irrelevant response & Frequency of irrelevant responses & Percentage of irrelevant response \\
\hline Passive & 98 & 23.3 \\
\hline Language transfer & 100 & 23.8 \\
\hline Intralingual interference & 85 & 20.2 \\
\hline Total & 283 & 67.3 \\
\hline
\end{tabular}

evant responses, with $23.8 \%$, followed closely behind with the passive, which accounts for $23.3 \%$ of total responses. Intralingual interference ranked last with $20.2 \%$. Based on the results attained from Tables 1 and 2, one could argue that Jordanian EFL learners encounter great difficulties grasping causative and inchoative constructions. This is best manifested by the fact that the total proportion of answers irrelevant to causative and inchoative constructions $(67.3 \%)$ exceeds by far the proportion of responses relevant to the use of the two constructions in question $(37.7 \%)$. In most cases, the participants either responded incorrectly to the test items or overgeneralized the passive over causative and inchoative constructions. It is fitting to depict the finding pertinent to research question two, which is formulated as follows;

\section{The Order of Acquiring Causative and Inchoative Alternations}

\section{Q2) Between the causative and inchoative constructions; which one is more readily to acquire?}

The answer to this question is revealed in Table 1 above. A close look at Table 1 shows that percentage of producing causative construction is $21.3 \%$, while the percentage of generating inchoative construction is $11.4 \%$. To examine whether this difference in the production of causative and inchoative constructions is statistically significant or not, t-test was used. The results of t-test are displayed in Table 3 below.

As demonstrated in Table 3, the $\mathrm{P}$ value is less than $0.05(p=0.00138<0.05)$, indicating that there is a statistical significant difference between the production of causative structures and inchoative structures. Those figures indicate that causative structures are more readily to acquire than inchoative structures. To put it in other words, the order of acquisition starts out with causative construction, then followed by inchoatives. As for research question three, it is formulated as follows;

\section{Language Transfer in the Acquisition of Causative- Inchoative Alternation.}

\section{Q3) To what extent does transfer from L1 (Arabic) contribute to the errors committed as acquiring causative and inchoative constructions?}

To answer this question, we need to look back at Table 2 . The table shows the participants' irrelevant responses, which include the passive voice responses, language transfer errors and intralingual errors. Language transfer errors account for $23.8 \%$ of the total responses, which is the highest proportion of irrelevant responses, whereas the passive responses
Table 3. Independent sample t-test

\begin{tabular}{lcc}
\hline & T value & P value \\
\hline Equal variances assumed & 1.675 & 0.001383 \\
\hline
\end{tabular}

constitute $23.3 \%$ and intralingual errors account for $20.2 \%$. Those results indicate the language transfer contributes significantly to the acquisition of causative and inchoative constructions.

\section{DISCUSSION OF RESULTS}

This part of the study endeavors to discuss thoroughly the results obtained after conducting data analysis. The discussion is presented with reference to the three research questions, in which an attempt to explain the results of each research question is made and some illustrative examples of subjects' responses are highlighted.

The results pertinent to research question one revealed that Jordanian EFL learners confront a huge challenge grasping causative and inchoative constructions, where the proportion of responses relevant to the use of causative and inchoative constructions was much less than the irrelevant responses. A close look at some students' responses might be necessary in showing the difficulties encountered by the respondents when acquiring causative/ inchoative alternations. In answering the items of grammaticality judgement and correction task, the respondents were asked to correct the erroneous items, so some answers were as follows;

1- The bread cut

-The bread was cut

-The bread is cutting

In answering item 1, the respondents' answers were as follows; passivizing the sentence, giving irrelevant answer or accepting the erroneous inchoative form as shown above. Most of the respondents were unaware that the verb cut cannot be used in an inchoative manner but requires an external participant bringing out the action but not showing the action as happening spontaneously.

2- The criminal killed

- The criminal was killed

- The criminal killed

Two answers were given to item 2, the first one is passivizing the sentence and the second is accepting the incorrect inchoative use as revealed in the above responses. It is obvious that the respondents lack the sufficient linguistic competence enabling them understand that the verb kill needs an external agent causing the change of state, thus it is causative verb. 
3- The city destroyed

- The city was destroyed

When responding to item 3 , the respondents either accepted the incorrect inchoative form or passivized the sentence. It could be inferred that accepting the erroneous inchoative form in 3 is attributed to the fact that the respondents are unaware that the predicate destroy needs an external participant to bring about the change of state and does not allow alternation.

The difficulty that Jordanian EFL learners encounter in understanding and producing causative-inchoative alternation stems from the fact that English and Arabic act differently when employing those constructions (Elnabih 2010). Specifically, some verbs in Arabic alternate with their English lexical counterparts, while others prohibit alternation. The results of this study are constituent with results of some previous studies on Arab learners of English (Elnabih, 2010; Zibin and Altakhaineh,2016). Those studies indicated that causative/inchoative alternation constitutes a learnability problem for Arab EFL learners.

With reference to research question two the results denoted that causative form is more readily to acquire than inchoative form. The vast majority of respondents opted causative sentences over their inchoative counterparts, when presented with the two alternatives. Those results are in line with Lavin and Rappaport (1994) who explain the difficulty in acquiring the inchoative form by saying that the causative structure is regarded in English as the basic form, whereas the inchoative form is counted as more lexically marked, so that L2 learners find difficulty learning the inchoative form.

The results of research question three displayed that Arabic language transfer is a determining factor in the acquisition of causative/inchoative alternations. More precisely, a great deal of errors arises from L1 influence. The examples below highlight some subjects' responses.

1- The man appear the rabbit

The majority of subjects accepted this sentence, considering it correct. The acceptance of such erroneous sentence in English can be ascribed to the subjects' mother tongue. In Arabic, the verb appear "yodhiro" can be used in causative form, while in English the reverse is correct.

2- The doctor died the patient

When answering, some students accepted this sentence. Such incorrect use of the inchoative verb die is traced back to Arabic, where Arabic allows alternating the verb die from inchoative form into causative form, while English does not allow such alternation. Most probably, errors resulting from L1 transfer can be attributed to differences between the sub-systems of two languages in contrast. The results of this question are in support of (Elnabih, 2010; Zibin and Altakhaineh,2016) who argue that Arabic negative transfer is the driving force of the errors committed as acquiring causative/inchoative alternations.

3- Tom happened the accident

- The accident was happened by Tom

Most respondents answered this question as follows; either accepting the erroneous inchoative form as in sentence 3 or wrongly passivizing the sentence. This error results from the respondents lack of knowledge that the verb happen neither takes the inchoative form nor be passivized.

\section{CONCLUSION}

This study aimed primarily at examining the perception of causative/inchoative alternations by Jordanian learners of English. As a secondary aim, the study attempted to investigate the order of acquisition of causative and inchoative constructions. Finally, the study investigated the role of L1 in the acquisition of causative-inchoative alternations. With the aim of obtaining the needed data, grammaticality judgement and correction task was distributed to 24 English majors at Amman Arab University in Jordan. The test was divided into three main parts; part one places emphasis on the causative construction, part two was devoted to measure learners' inchoative competence and part three was designed to test learners order of acquisition of the two constructions in question. Having analyzed the data obtained from the respondents statistically, the results showed that Jordanian EFL learners do not have a good command of English causative and inchoative constructions. In other words, the respondents have performed poorly in understanding and producing causative and inchoative forms in English. The results additionally indicated that the respondents acquire causative constructions earlier than its inchoative counterparts. It was also found that language transfer is a determining factor in the acquisition of causative and inchoative structures.

\section{REFERENCES}

Ahaj, A. (2015). The ambit of English/Arabic Translation. A practical and Theoretical Guide for English/Arabic Translator. Author Academic Publishing.

Bailey, N, Madden, C \& Krashen, S. (1974). Is there a "natural sequence " in the adult second language learning? Language Learning, 24, 235-43.

Can C and Altunkol, E. (n.d).To alternate or not to alternate? L2 acquisition of English causative/inchoative transitivity alternations. Qukurova University.

Chaudron, C. (1983). Research in metalinguistic judgments: A review of theory, methods and results. Language Learning, 33, pp. 343-377.

Dulay, H.C \& Burt, M. (1974). A new perspective on the creative construction process in children. Language learning, 24, 235-278.

Dziemianko, A. (2006). User-Friendliness of Verb Syntax in Pedagogical Dictionaries of English. Germany. Lexicographica Series Maior

Ellis, R. (1985). Understanding second language acquisition. New York: Oxford University Press.

El-nabih, H. (2010). The acquisition of the English causative-inchoative alternation by Arabic native speakers (Doctoral dissertation). Available from ProQuest Dissertations \& Theses database. UMI No. 343221.

Fries, C. (1957). The Structure of English. New York: Harcourt, Brace and Company.Lado, R (1957) Linguistics 
across cultures Ann Arbor, MI University of Michigan press

Gass, S and Selinkar, L. (1992). Language Transfer in Language Learning. USA. Benjamins Publishing Company.

Levin, B. (1993). English verb classes and alternations. A preliminary investigation. Chicago: The University of Chicago Press.

Liao, E. (2010). An Investigation of Cross-linguistic Transfer in EFL Learners' Phraseology. (Doctoral Dissertation). Available from ProQuest Dissertations \& Theses database. UMI No 3401772.

Levin, B., \& Rappaport Hovav, M. (1994). A Preliminary Analysis of Causative Verbs in English. Lingua, 92, 35- 77.

Montrul, S. (1999). Causative errors with unaccusative verbs in Spanish as a second language. Second Language Research, 15(2), 191-219.

Montrul, S.(2001a). "Causatives and Transitivity in L2 English”. Language Learning 51(1), 51-106.

Montrul, S.(2001b). “Agentive Verbs of Manner of Motion in Spanish and English as Second Languages". Studies in Second Language Acquisition 23, 145-151.

Moore, M.M.P. (1993). SLA of Lexically Constrained Transitivity Alternations: Acquisition of the Causative Alternation by SLLs of English. Unpublished Ph.D. dissertation, University of South Carolina.

Odlin, T. (1989). Language transfer: cross-linguistic influence in language learning. New York Cambridge University press.

Pinker, S. (1989). Learnability and cognition: The acquisition of argument structure. Cambridge: MIT Press.

Pinon, C. (2001). A Finer Look at the Causative-Inchoative Alternation. Proceedings of Semantics and Linguistic Theory 11. Ithaca, NY: Cornell Linguistics Circle.
Richards, J. C., Platt, J., \& Platt, H. (1992). Dictionary of Language Teaching \& Applied Linguistics. (Second Edition), Harlow, Essex: Longman.

Rubin, A. and Babbie, E. (2009). Research Methods for Social Work ( $7^{\text {th }}$ ed). USA: Linda Schreiber.p.520.

Samardzic, T and Merlo, P. (2012). The Meaning of Lexical Causatives in Cross- Linguistic Variation. Linguistic Issues in Language Technology, 7(12).

Schäfer, F. (2009). The causative alternation. In Language and Linguistics. Compass, 3, 641-681. Blackwell Publishing.

Simic, A. (2010). L1 interference in the perception and production of English Vowels by Arabic Speakers (Doctoral Dissertation). Available from ProQuest Dissertations and Theses Database. UMI No 3463872.

Tabib-Zadeh, O. (2006). Verb capacity and basic sentence constructions in Modern Persian. Tehran: Markaz Publication.

Tahaineh, Y. (2010). A study of Arab EFL University Students> Errors in the Use of Prepositions. MJAL2:1JANUARY2010.ISSN0974-8741,

Yip, V. (1995). Interlanguage and learnability. Philadelphia, PA: John Benjamins.

Zibin, A and Altakhaineh, A. (2016). Acquiring the English Causative Alternation: Evidence from the University of Jordan. International Journal of Applied Linguistics \& English Literature, 5(3).

Zobl, H. (1989). Canonical typological structures and ergativity in English L2 acquisition. In Gass, S. and Schacter, J., (eds.), Linguistic perspectives on second language acquisition, pp. 203-21. Cambridge: Cambridge University Press.

Note: We arrange the table according that table citation and as per our journal style. Please check and advice. 